\title{
Atlántica: La renovación plástica gallega
}

\author{
Paula Mariño *
}

\begin{abstract}
RESUMEN
ABSTRACT

Atlántica, movimiento artístico gallego

Atlántica, artistic Galician movement surgido a principios de la década de los ochenta, con la intención de crear un arte de carácter internacional estuvo marcado por sus vinculaciones a una poética romántica. por los cambios generados en el contexto artístico español y los que se dieron en cuanto a la nueva estética internacional, que afectó a la concepción del arte que se gestó a principios de dicha década. Estos condicionamientos provocaron una serie de rasgos fundamentales y unos planteamientos en cuanto a su gestación y su poética, que definen su interés en la creablossomed in the beginings of the 80's, whit the purpose of creating internacional art; was related to romantic poetry, due to the changes generated wituin the spanish artistic contextas well as the ones happening wituin the international aesthetic values, which influenced to the idea of art born in the beginings of the above mentioned decade. All these watters provoked a serial of fundamental features and conceptions related to it's poetics and genetics, that define their interest on the creation of a vanguardist art.
\end{abstract} ción de un arte de vanguardia.

\section{INTRODUCCIÓN}

Atlántica surge no como un movimiento -en el sentido artístico- sino como un grupo humano que pretendía "discutir el país", y crear un ámbito de reflexión en cuanto a los métodos y las poéticas de la plástica. Su

* Tercer ciclo. Departamento de Historia del Arte. UNED. 
actuación fue corta, tan sólo se realizaron cinco exposiciones comisariadas por el colectivo - desde el año 1980 hasta 1983 - en muestras siempre de carácter multidisciplinar, que abarcaban pintura, escultura diseño y arquitectura, y donde tuvieron cabida tanto artistas «senior» como jóvenes, pero donde primaba la pintura y la individualidad como rasgos distintivos. Si bien es cierto que su poética se acerca a planteamientos de tipo nacionalista en cuanto a términos de identidad cultural y la reivindicación de un cierto genius loci, no lo es menos la necesidad de una vuelta al pasado enmarcado dentro de propuestas de tipo internacionalista. Así, el arte gallego en los ochenta mira al pasado en la intención, a través de la recuperación de símbolos y signos de carácter mítico - relacionados con el mundo precristiano o céltico- y de una plástica y operativas -en el caso de la escultura - ligadas a la piedra o a la madera, de renovar la plástica a partir de una mirada a planteamientos técnicos vinculados al Expresionismo Abstracto americano - en el caso de la pintura- y más en concreto al Action Paintig, en cuanto a la utilización de signos de una fuerte carga expresiva y de una exacerbada rotundidad, para realizar un arte de vanguardia.

\section{ATLÁNTICA Y EL ROMANTICISMO}

La vinculación que Atlántica posee con el Romanticismo, tiene como una de sus bases fundamentales la teoría de Robert Rosenblum ${ }^{1}$, sobre las relaciones que ciertas tendencias y artistas mantienen con la corriente romántica, en cuanto a una serie de similitudes formales -en distintos artistas separados tanto en el tiempo como en el espacio a lo largo de varios siglos- y un sentimiento religioso de búsqueda, así como semejanzas tanto en el sentimiento como en la intención, que provocarían analogías en cuanto a la extensión estética del color o la intención de aislar elementos primordiales de la naturaleza. Estos románticos se asociarán a un sentimiento religioso de índole panteísta, con relación a Dios, y recurrirán a una iconografía no tradicional cristiana o judaica, sino particular, en la cual la evocación del Todo y la Nada estaría muy clara en la utilización de una serie de símbolos e iconos, que son claramente subjetivos. De hecho los paisajes románticos son claramente simbólicos, incluso también en los artistas vinculados al Action Painting americano como Rothko o Barnet

\footnotetext{
Véase Rosenblum.,R.., La pintura moderna y la tradición del romanticismo nórdico. Madrid: Alianza Editorial, 1993, págs. 15 y ss.
} 
Newman. De este modo este sentimiento religioso llevaría a estos artistas adscritos a esta poética romántica a un misticismo, teñido de una gran simbología, en el cual existiría una cosmogonía personal y subjetiva.

De este modo el romanticismo existiria en dos polos: en uno la empatía con las fuerzas naturales y en otro en cuanto a las construcciones simbólicas, que provocarían un iconismo que aparecería tanto en los primeros románticos como en artistas posteriores a este movimiento; en este sentido los artistas de Atlántica se acercan a esta estética romántica así como a otros aspectos de esta tendencia que define Rosenblum y que relacionarían al Atlantismo con esta corriente: el viaje, la comunicación con el misterio la creación de nuevos dioses, la relación con las fuerzas naturales y la vinculación a la tierra. En este sentido la llamada Falacia Sentimental es decir la relación que los románticos establecen con los elementos de la naturaleza como los árboles, término empleado por Ruskin ${ }^{2}$ en su obra «Modern Painters", con respecto a la atribución de sentimientos humanos a sujetos no humanos- se puede rastrear en artistas como Francisco Leiro con sus «Homos» (fig. 1), en la creación de figuras momumentales con la utilización de grandes troncos de madera, o en Antón Patiño, en sus "Mexonas» (fig. 2) troncos de árbol metamorfoseados en mujeres.

La relación del artista romántico con el misterio, con lo sobrenatural que lo sobrecoge, provoca la creación de la obra como experiencia sacra, en una fusión entre arte y vida, dando a lugar a la creación de símbolos y de un universo personal.

En artistas como Friedrich o Rothko, esta religiosidad se relaciona con ámbitos cercanos a la tradición judeo-cristiana, para a través de una cosmogonía propia acercarnos a la divinidad, en la búsqueda de un Dios en todo, de un panteísmo. Esta intención reformadora no existe, sin embargo en los artistas de Atlántica, ya que aunque aparezca un acercamiento a lo religioso, éste se vehicula a partir del mito y su relación con las fuerzas primigenias en los personajes de Francisco Leiro y Antón Lamazares, así como en las terminologías paganas de Menchu Lamas (fig. 3) y Antón Patiño.

Otro aspecto importante sería la creación de nuevos dioses a partir de elementos naturales, el gusto por las situaciones límites - horror vacui-; las figuras enfrentadas al abismo; la simplicidad en la forma, es

\footnotetext{
2 Véase Rosenblum, R., «Tal motivo podría llamarse, por usar la expresión de John Ruskin en Modern Painters, la "pathetic fallacy", la falacia sentimental. Ruskin se refería en ejemplos literarios, a la curiosa atribución de sentimientos humanos a sujetos no humanos», op. cit., pág. 42.
} 


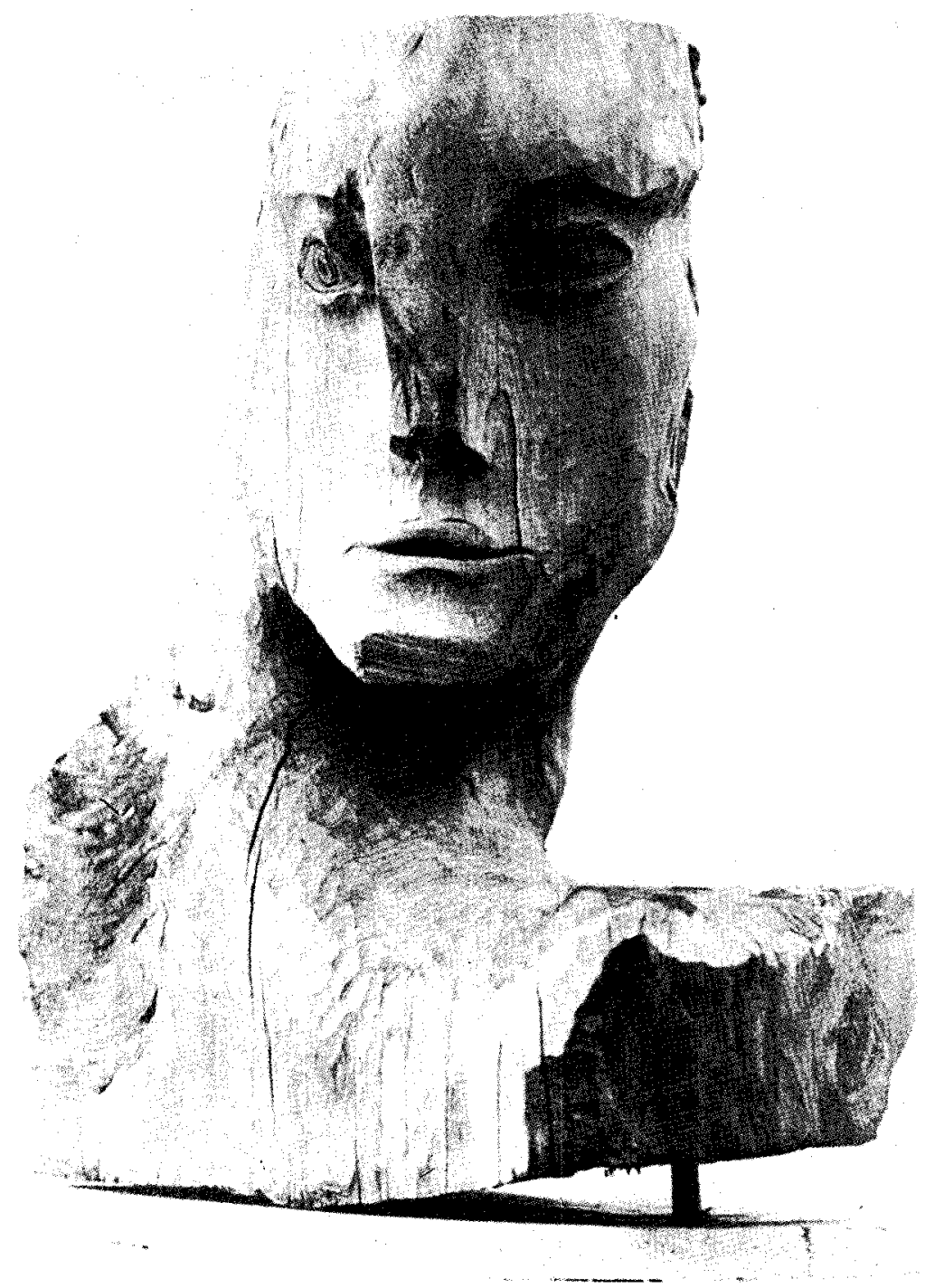

Fig. 1. FRANCISCO LEIRO. Testa (Cabeza), 1984. Madera policromada, $51 \times 84 \mathrm{~cm}$.

decir, la reducción de formas abiertamente abstractas; la depuración del lenguaje y la desmaterialización del objeto en aras de su subjetividad. Un arte que se dirige a las emociones en un intento de explicar lo inexplicable, en relación con la estética de lo sublime y la necesidad de ruptura con 


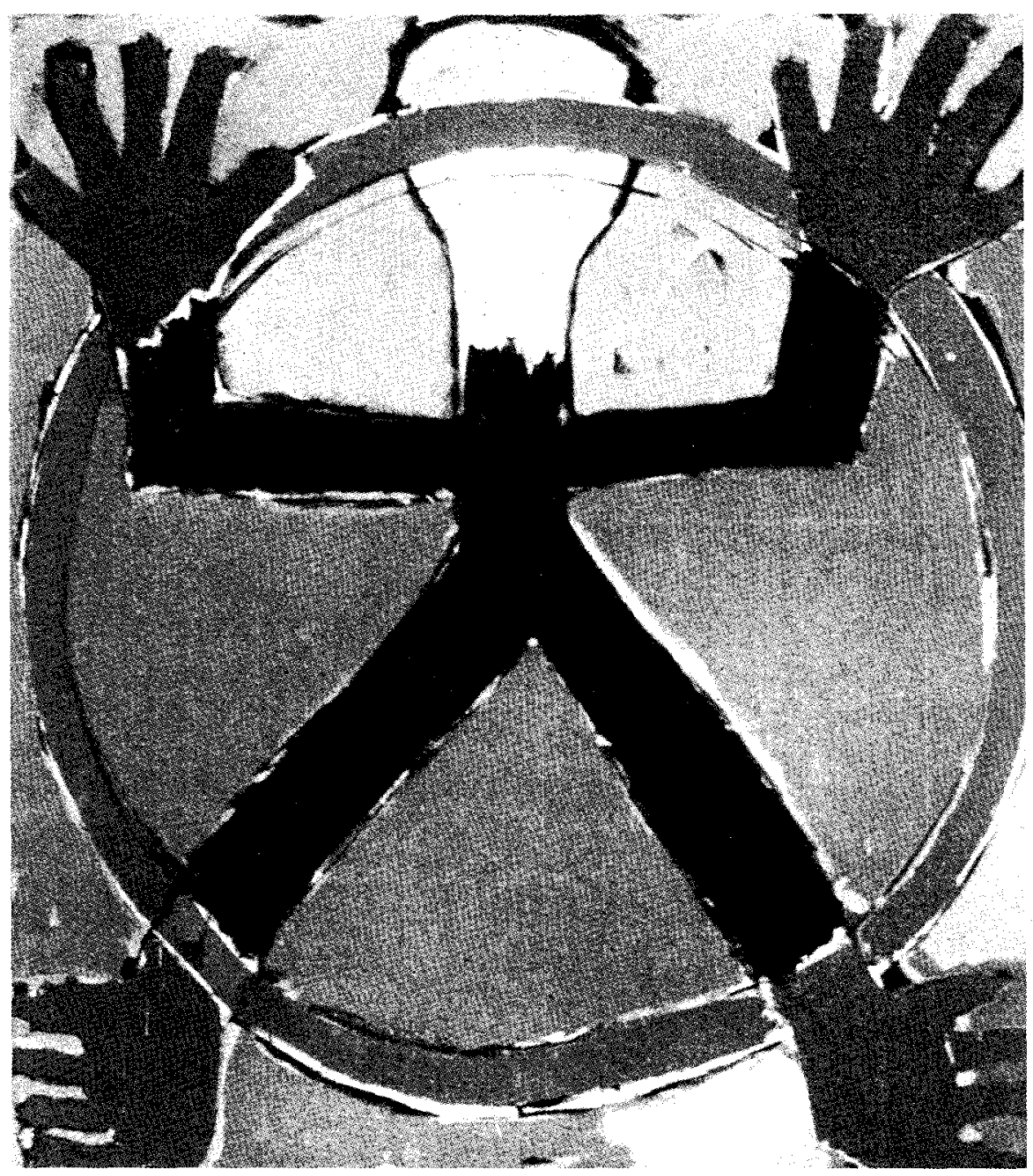

Fig. 2. ANTÓN PATIÑO. A Mexona,1982. Acrílico sobre tela, $260 \times 195 \mathrm{~cm}$.

estéticas anteriores, que en Lamas y Ángel Huete se relacionaría con un cierto aliento poético, en Antón Patiño (fig. 4) con la estética del vacío y en Antón Lamazares en una inmediatez lírica marcada por la introspección.

Estos artistas buscan un ordenamiento del mundo mediante la inclusión de símbolos que evocan a los dioses de la tierra, en la intención de crear contextos simbólicos para la comunidad, incluso espacios sagrados. Hay una necesidad de regeneración ante el caos que se provoca en 


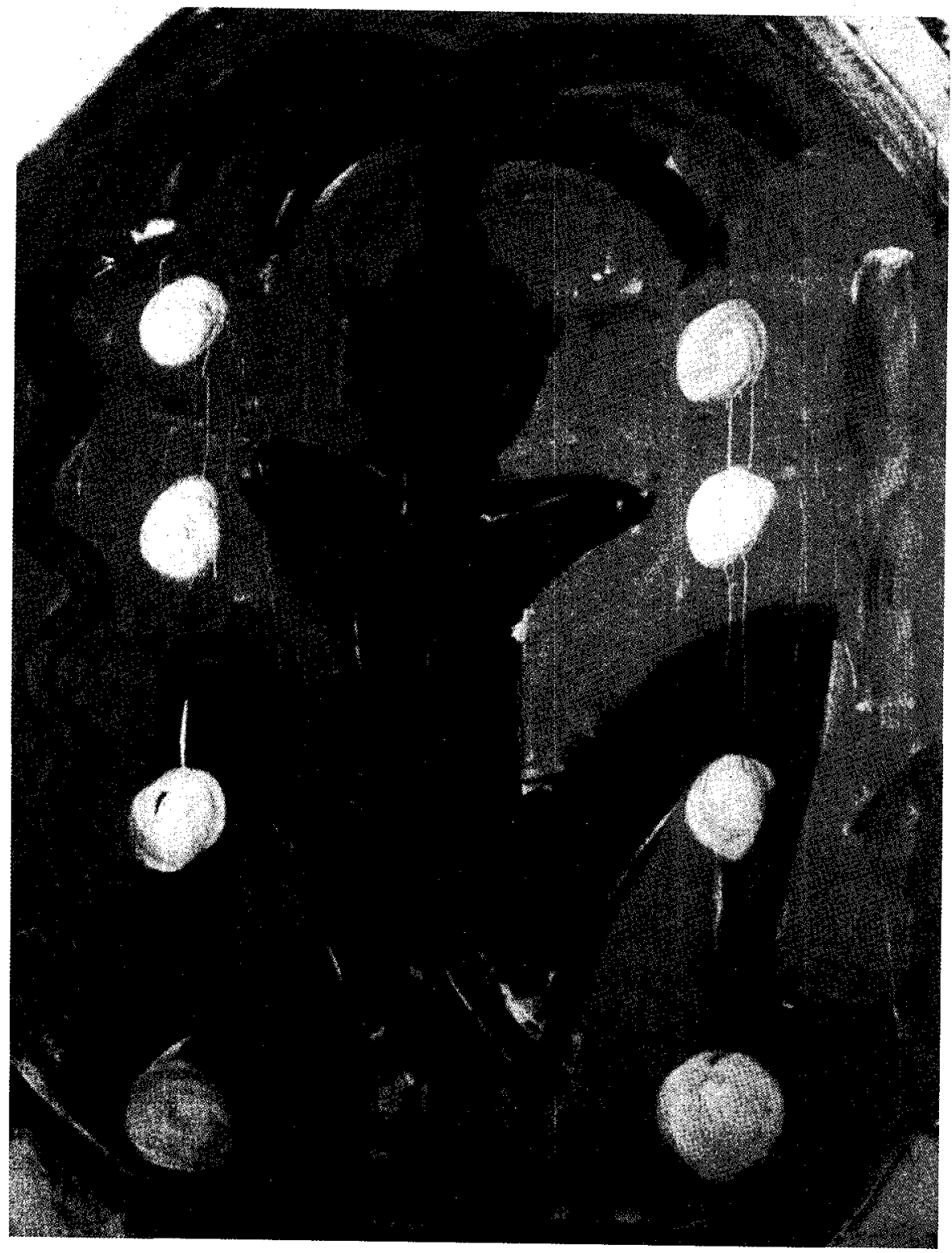

Fig. 3. MENCHU LAMAS. S/T, 1982. Acrílico sobre lienzo, $230 \times 200 \mathrm{~cm}$. 


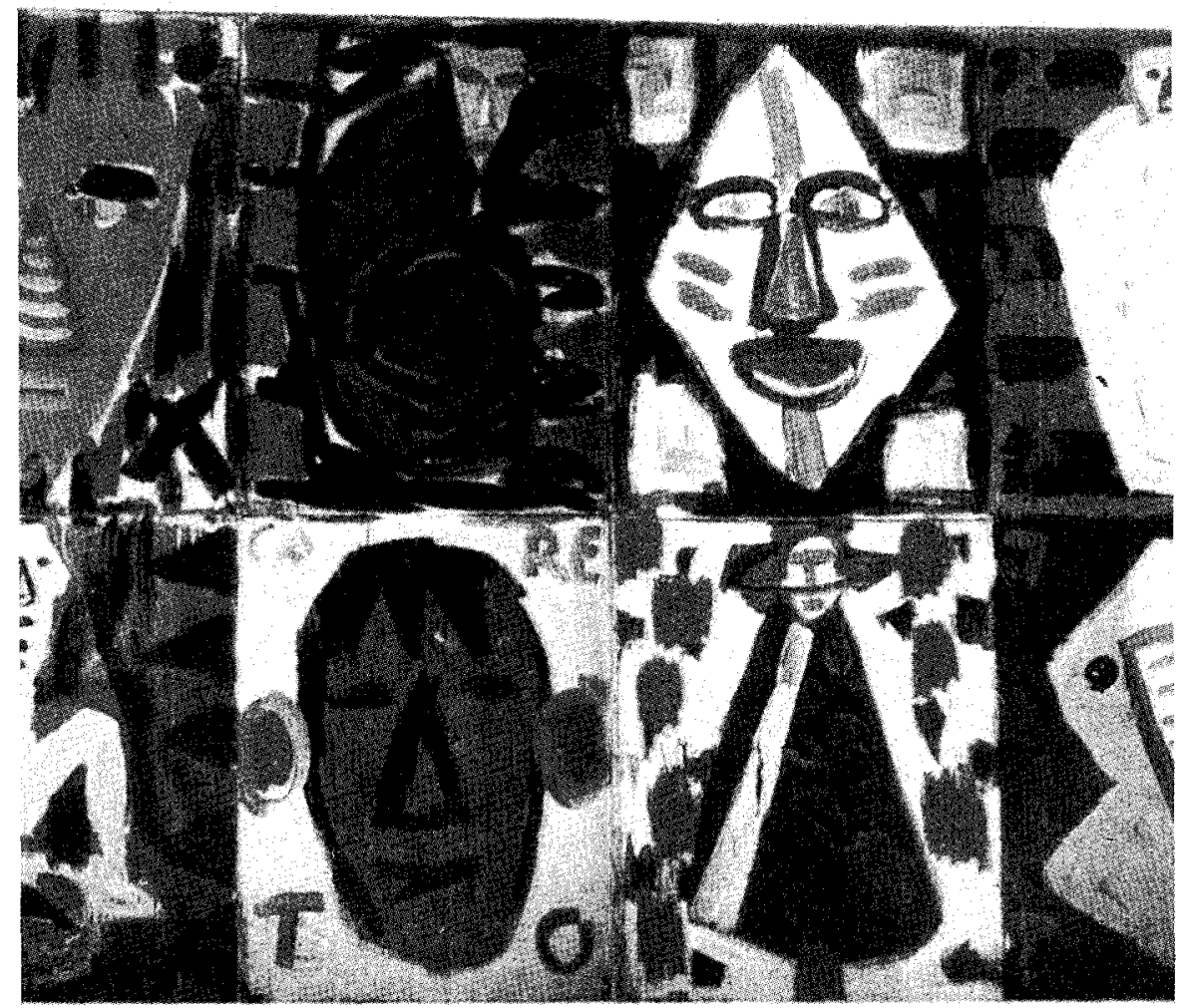

Fig. 4. ANTÓN PATIÑO. Potpourri, 1983. Acrilico sobre lienzo, $260 \times 339, \mathrm{~cm}$. (Detalle).

el universo, y esta regeneración se realiza a través de iconos heredados que remiten a una tradición anterior ligada a los ancestros, a la tierra, en un búsqueda de mutación total de forma y contenido. La perpetuación de un panteísmo romántico que llevará a versiones metafóricas de elementos románticos como el sol, la luna ${ }^{3}$ o las ventanas es un elemento recurrente en algunos artistas de Atlántica. Esta relación con la ventana remite también al sentimiento romántico del viaje, no sólo un viaje físico sino también un viaje interior o arqueológico a través de símbolos y signos en la búsqueda de una sobriedad y una pureza que se acercan a un misticismo de índole romántica. Es una mirada hacia el exterior, una mirada contempladora; las puertas, las ventanas, se remontan a esos espacios vacíos e infinitos. La ventana y todo el campo semántico a que

3 «Esas lunas y soles tendrán muchos más adoradores» Véase Rosenblum, R., op. cit., pág, 21 
nos remite, es un puerta de acceso hacia una infinitud inconmensurable, que podría relacionarse con el paisaje; y en este caso el artista se convierte en un viajero, un nómada, de tal modo que esa errancia sea hacia el pasado, al inconsciente o hacia lo prehistórico. Guillermo Monroy (fig. 5) nos acerca con sus ventanas a esa necesidad del viaje, hacia su subjetividad, y nos remite a otras ventanas de artistas románticos como Friedrich o Newman.

El uso del color, está también vinculado en Atlántica a la estética romántica ${ }^{4}$, el uso del azul asociado a la experiencia sobrenatural, desmaterializa los objetos, religándose a un mundo metafórico. Su relación con el color se refiere al mismo tiempo al gusto por un tono cromático que tiende a lo indeterminado, excluyendo los colores planos, alejados de la transparencia visual que los apartaría del mundo mediterráneo y los acercaría en cambio a un universo nórdico, que definen artistas como Freixanes ${ }^{5}$ y Antón Patiño, con respecto a la reivindicación de una Galicia Céltica o de un país nórdico, del que hablaba Vicente Risco.

Todas estas referencias al Romanticismo avalan la teoría de la adscripción de Atlántica a un vocabulario romántico. Si realizamos una globalización de todas estas características, hay dos aspectos que parecen estar claros: su pertenencia a un mundo atlántico geográfico y nórdico, que le confiere características del movimiento romántico y la influencia de los artistas americanos del Action Paintig. Los artistas de Atlántica no sólo están adscritos o redefinen una tendencia romántica por su pertenencia al mundo nórdico, sino que además poseen referencias muy claras al Expresionismo Abstracto USA relacionados también con el Romanticismo y herederos de una misma tradición. Sin embargo esta vinculación con los americanos, está en relación más con la forma que en el contenido, en la búsqueda de una rotundidad y una fuerza de las imágenes; ya que la interacción de los americanos con lo espiritual al construir la obras, se realiza para tratar de expresar esa unión con lo sobrenatural, y esto es obviado por los atlantistas, que se relacionan más con lo pagano, con el mito, que con una espiritualidad tradicional.

\footnotetext{
4 El color azul, se convirtió a partir de Novalis, en un símbolo que perduró en el romanticismo alemán, artistas ligados en sus orígenes con una espiritualidad romántica como Vincent VAN GoHG - Piet MONDRIAN, situarán sus obras en fondos azules para sumergirnos en un mondo metafórico, donde el color actúa como un referente del viaje trascendental de la materia al espíritu. A propósito de Novalis, véase la cita sobre este tema en: Craston, M., El Romanticismo. Grijalbo Mondadori. Barcelona, 1997, págs. 43 y 44

5 Seoane, X., Identide e convulsión. Palabra e imaxe da nova arte galega. Ed. Do Castro. A Coruña, 1990, pág. 127.
} 


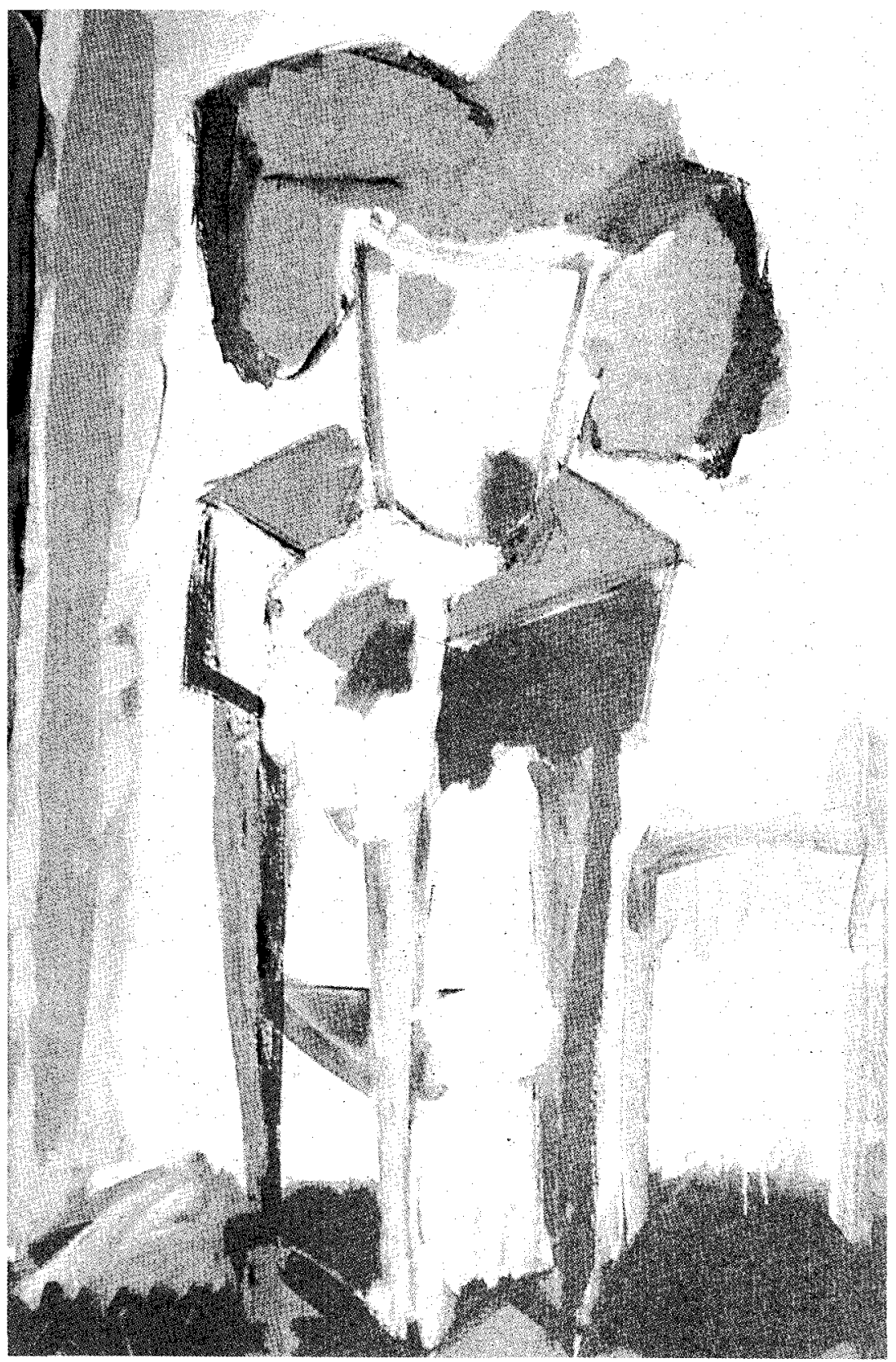

Fig. 5. GUILLERMO MONROY. Ventana. 1982. Acrílico sobre tela, $97 \times 130 \mathrm{~cm}$. 


\section{PLANTEAMIENTOS SOBRE EL ARTE DE LOS OCHENTA}

El arte en la década de los ochenta se generará a partir de una serie de factores y de rasgos fundamentales, que tendrán vital importancia para entender la estética Atlantista. En primer lugar, como señala Calvo Serraller ${ }^{6}$ habría que reseñar los cambios que se generaron en la sociedad española desde el punto de vista de la sociología; en este sentido la llegada de la democracia facilitará el acceso a la información. Hasta ese momento debido a las carencias existentes, el artista en España no podía conectar con el arte de vanguardia, será a partir de la década de los sesenta cuando se iniciará este acceso a la información y posibilitará los cambios que se harán efectivos en los ochenta. En realidad hasta la década de los ochenta, los intentos de hacer un arte de vanguardia chocaba con una realidad más bien pobre en nuestro país, no existía un verdadero mercado, ni un coleccionismo serio, ni un verdadero interés por parte del estado en promover un arte de tendencia internacional y vanguardista. Sin embargo, a partir de estos cambios que se generaron en España, aparecerán una serie de realidades que hasta el momento eran impensables: el arte pierde toda referencia a una iconicidad religiosa tradicional y se revalorizará en este momento el mito y la cultura precristiana del país. El arte se vuelve más cosmopolita, los artistas se consideran ya ciudadanos del mundo y comienzan a viajar, repartiendo el tiempo entre España y el extranjero.

Y este cambio será debido a la consolidación de la democracia que provoca una gran vitalidad en el mundo artístico, ya que las instituciones promoverán un arte de vanguardia a partir de exposiciones de gente joven, animadas por la masiva respuesta popular ante estas macroexposiciones y exposiciones de arte joven, debido a que las instituciones tanto públicas como privadas, comenzaron a desarrollar una política de muestras tanto de arte español como extranjero.

Al mismo tiempo, estas mutaciones en el campo socioeconómico vienen refrendadas por un cambio en la estética. La estética de los ochenta estará marcada por la caída de la «Estética de la Constatación» 7, de carácter evidentemente científico, que había permanecido bajo el yugo de la formalización y de la racionalización, rechazando la interpretación junto con la subjetividad. Esta estética estaba agotada ya a mediados de los

6 Calvo Serraller, F., Escultura española actual: una generación para un fin de siglo. Fundación Lugar. Madrid, 1992, pág. 32.

Véase MARCHÁN FIz, S., La estética en la cultura moderna. Alianza Editorial. Madrid, 1987, pág. 241. 
setenta, debido al cuestionamiento de la racionalización ante la crisis de los modelos sociales y político-económicos. Este cambio viene dado por varios momentos: en primer lugar la consideración del arte en las coordenadas del símbolo y la percepción del arte como algo desligado del conocimiento científico. En segundo lugar, el concepto de «Asemiosis» ${ }^{8}$ aportado por U. Eco, basado en la no relación entre la obra y sus contenidos, en los cuales se reivindicará la revalorización del protagonismo del artista y del espectador como activador de la obra de arte. Es decir, se abandona la concepción de la obra de arte como si tratara de un sistema lingüístico o de comunicación, en el cual la percepción y la subjetividad no tuvieran lugar. $Y$ en tercer lugar la exploración de la obra como juego, articulado por la percepción, dando lugar a que el espectador participe en el «lanzamiento de dados" ${ }^{9}$.

Se apoyará además en los ochenta la interpretación de la obra de arte a partir de la metáfora, buscando mecanismos abiertos a la hetereogeneidad y la dispersión, tomando partido a favor del símbolo en el arte. Se tenderá a una cultura de mosaico, con un gran eclecticismo mientras que el pluralismo será un rasgo común. Cabría preguntarse aquí, si no será este cuestionamiento de la razón la vuelta a un nuevo romanticismo del que habla Marchán Fiz ${ }^{10}$ al enumerar ciertas características de este movimiento, aspectos que parece se vinculan a la estética de los ochenta y que podríamos al mismo tiempo referir al grupo Atlántica.

\section{ATLÁNTICA Y SU PECULIARIDAD}

Atlántica presenta una serie de constantes en sus planteamientos, marcados por dos aspectos fundamentales: su relación con el expresionismo abstracto americano y con los movimientos pictóricos y tendencias que en ese momento surgían en Europa.

La marcada influencia del expresionismo abstracto americano, en sintonía con el resto de Europa, debido al colonialismo cultural existente desde los sesenta, es clara en los atlantistas, y en particular del Action Painting, vinculándose a éste en la necesidad de un cambio de relación con el espíritu pictórico y en la intención de desarrollar tensión entre forma

ECo, U., Tratado de Semiótica, págs. 429 y 436, citado por MARCHÁN FIZ, S., ibíd, pág. 243.

9 MARCHÁN FIZ, S., op. cit., pág. 244. Expresión utilizada en el sentido de la inclusión del juego dentro del código de interpretación de la obra.

10 MARChán FIZ, S., ibíd, pág. 115. 
y color en una investigación constante, pero que sin embargo se aleja de los americanos en la no asunción de una estética de los sublime reivindicada por aquellos; ya que si bien existe una fascinación por el modo de operar de los americanos, no existen planteamiento espiritualistas en la búsqueda de Dios a partir del arte. Así, los artistas de Atlántica se acercan a la religión desde el mito ${ }^{11}$, en una búsqueda de sus raíces, que lo relacionará con la subjetividad en la intención de encontrar un lenguaje universal.

Ya antes de los ochenta, se empezó a cuestionar la validez del arte para acceder al conocimiento, esta conciencia había provocado la aceptación del fracaso que afectó al objeto artístico, generando una crisis. Al mismo tiempo, hay una vuelta a la autonomía de lo artístico, cortando los lazos de tipo ideológico que la obra de arte había mantenido hasta entonces con la realidad. Dentro de este contexto se mueven en los ochenta dos corrientes artísticas: el movimiento alemán de los «Nuevos Salvajes» y la Transvanguardia Italiana.

Los alemanes asumirán una tradición cultural y un estética romántica y expresionista como reafirmación de los valores de su propia identidad, en la creación de un arte asocial, cuya única responsabilidad radica e su posición frente al trabajo que realiza. Serán obras que no precisan de incorporar ninguna idea de función, aisladas y autónomas. La relación de Atlántica con este movimiento se basará en el interés por reclamar un arte internacional alejado de estéticas «provincianas» -aunque el arte alemán es marcadamente «nacional»-, en la recurrencia de elementos del pasado de la mitología precristiana o pagana (fig. 6), en las que estén presentes la alquimia o el terruño, en una revisitación de antiguos mitos, a partir del uso de un color expresivo o del graffiti. En los artistas de Atlántica encontramos un retorno esencial a la figuración, a la realidad retomada, que -como los alemanes-partiendo de un panteísmo pictórico, revitalizan sus raíces en la búsqueda de la identidad del país. Existe una búsqueda de nuevos contenidos en una relación arte-vida, pero se sigue tomando el expresionismo como pauta,

\footnotetext{
11 El mito será el discurso dinámico que resuelve la pluralidad de los deseos y de las realidades que motivan los actos y los sueños de los hombres. Será al mismo tiempo una reafirmación del hombre ante lo desconocido, ante las fuerzas naturales y los fenómenos que lo sobrecogen y a los que no encuentran una respuesta racional. Antes estos, el hombre crea entonces dioses, mitos. La narración mítica va construyendo con la comunicación el decorado mítico y los discursos y determinaciones del imaginario que se configuran como recurrencias de la cultura, y por lo tanto, como privilegiadas claves de lectura de los cambios y de las aportaciones estéticas en ella localizados.
} 
Atlántica: La renovación plástica gallega

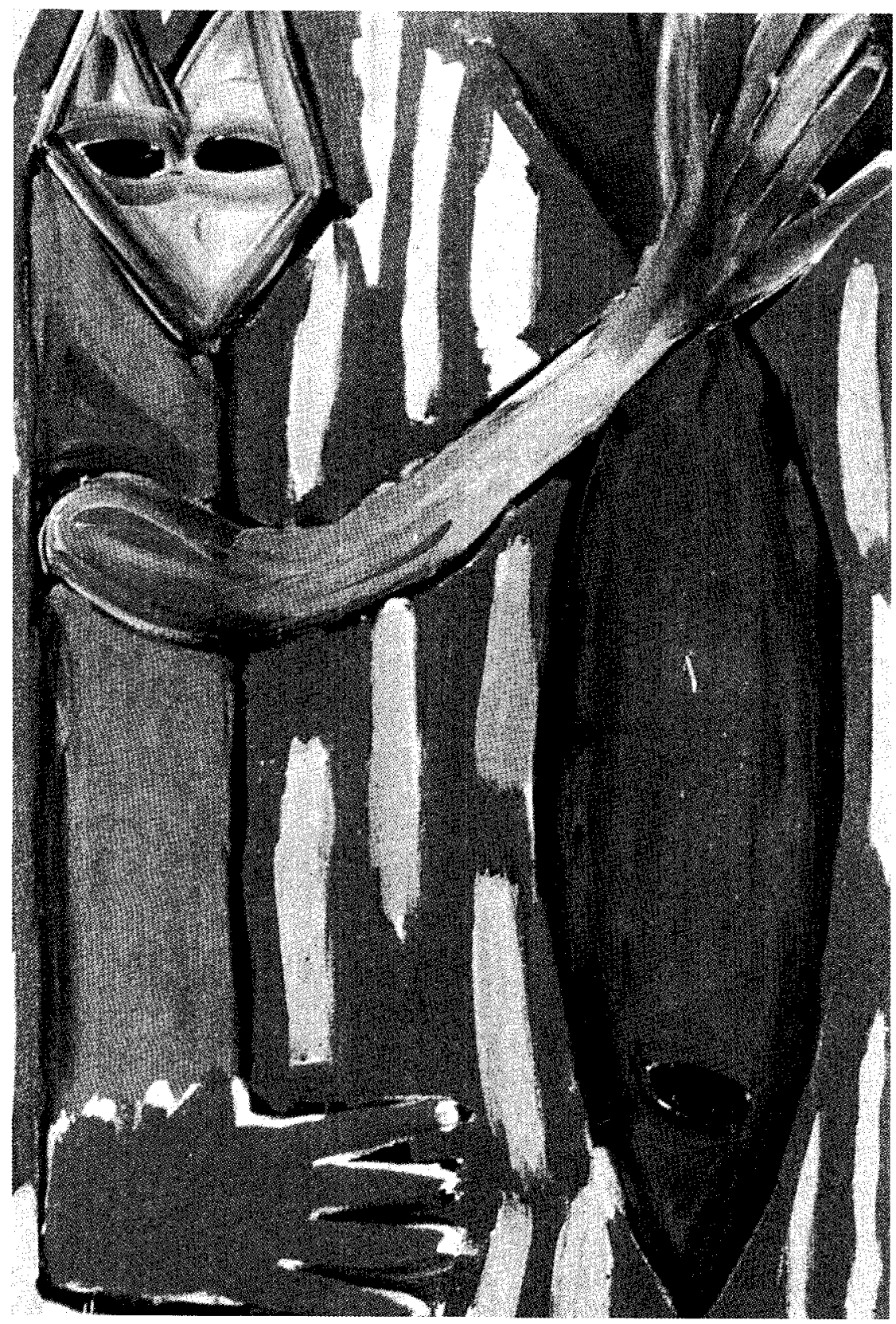

Fig. 6. MENCHU LAMAS. Home con peixe (Hombre con pez), 1983. Acrílico sobre lienzo, $230 \times 150 \mathrm{~cm}$. 
tanto en la forma como en el color o la composición, en la que la narración forma parte de su poética, contra aquellos artistas de poética incolora, fría o inexpresiva, en una reivindicación clara en los ochenta de la vuelta a la pintura. Otro factor importante será la independencia del artista. Los artistas alemanes reivindican la necesidad de trabajar dentro de su individualidad, en una actividad incesante; de hecho, el arte alemán de este momento es menos rico en movimientos colectivos que en personalidades, aunque actúen dentro de una poética similar; cuando hablamos de independencia del artista, nos referimos a la reivindicación del deseo, de la invención, en unos postulados esencial mente intuitivos, cercano a una estética de los sublime, que sin duda provoca, una individualización, una resistencia. El artista ya no depende de un movimiento luchador, el artista trabaja solo. Este carácter no reivindicativo en lo social, aparece en cierto modo en los artistas de Atlántica; retoman el pasado mítico, la conciencia de su diferenciación, como parte de sus propuestas a favor de una identidad basada en el mito o tribal, pero siempre desde el ámbito de la subjetividad. Su análisis de la realidad anterior se basa en la apropiación de símbolos y en la creación de iconos de contenido mítico para beber del pasado, pero siempre desde una individualidad y a partir de lo instintivo, en una estética de la intensidad y de lo inabarcable.

Asimismo, los artistas italianos de la Transvanguardia, revalorizarán una pintura figurativa alejándose en sus poéticas de lo imaginario; el individuo hurga en la memoria de su pasado y se reapropia de mitos e imágenes de su propia mitología. Hacen una relectura de la obra de arte a partir de la historia del arte de su país y de su gente, en un regreso al individuo -este aspecto tiene un gran punto de contacto tanto con los alemanes como con los gallegos-, a los valores nacionales y a la iconografía clásica. El artista crea - al igual que la mayoría de los artistas de los ochenta - sin preocuparse por la dialéctica, liberado de ilusiones ideológicas, ofreciendo imágenes que no rechazan el placer de la narración y de la representación de un mundo onírico, mitológico e intimista, mientras ajeno a toda preocupación, evoca un universo atemporal, con interés por una «pintura culta» en la alusión a citas pictóricas. Sin embargo los Atlantista se alejan de bs italianos en su modo de acercarse al pasado, mientras que estos recuperan un pasado mitológico y culto, con referencias a citas pictóricas en un guiño elitista al espectador, aquellos retoman como los alemanes, un pasado mitológico "precultural» -referido a una tradición germánica cercana a la asunción de unas fuerzas originarias o primigenias que evocan estadios de energía- en la reafirmación de una cultura propia, creando iconos propios y subjetivos. 
Mientras que los italianos revalorizan el concepto de oficio, y se vuelve a las técnicas tradicionales: carboncillo, lápiz, perspectivas, sombras, frescos o barnices; los artistas gallegos, generan una pintura en la que los nuevos materiales como el acrílico, representan esa necesidad de valoración y de incorporación de técnicas más novedosas que las antes utilizadas en el endémico arte gallego, que se perpetuaba tanto en las formas como en el modo de ejecución; de este modo hacen su aparición el cartón como soporte (fig. 7) los graffiti, o el papel. Caso especial en el uso de los materiales, es el de los escultores, que se acercan más a los materiales tradicionales gallegos: la piedra o la madera (fig. 8). Podemos sin embargo encontrar puntos de encuentro en dos aspectos: la vuelta a la pintura-pintura y la fluctuación de ambos en el territorio antropológico y las mitologías individuales.

\section{LA POÉTICA DE ATLÁNTICA}

El nacionalismo aparece como redefinión del lenguaje propio en la búsqueda de la identidad, en relación con el interés de los eruditos en poner su actividad intelectual al servicio del espíritu local. Se acerca al concepto de Volksgeist, en cuanto a su carácter romántico: el individualismo, el triunfo de lo subjetivo y el gusto por lo popular. Estas afirmaciones nacionalistas parten siempre de identificaciones de tipo cultural, conviven en los ochenta con la creación de un arte multirracial y ecléctico, que como señala Félix de Azúa ${ }^{12}$, apuntaba a un mestizaje alejado de un carácter programático cerrado. De hecho este auge del nacionalismo, según Marchán $\mathrm{Fiz}^{13}$, surge como una necesidad de afirmación ante la pérdida de referentes debido a la fuerte crisis de identidad, que estaría en relación con los rasgos románticos que algunos autores encuentran en los ochenta: la subjetividad y las maneras individuales que primaran sobre el concepto de "estilo".

Así, la autoafirmación como parte de la aldea global parte de un cierto nacionalismo o regionalismo en muchos casos y desemboca en los ochenta en diversas exposiciones en España y en la creación de ciertos grupos como el vasco y el gallego - de carácter más heteróclito-, aunque algunos autores como Valeriano Bozal u Horacio Fernández consideren que el

\footnotetext{
12 AzúA, F., El aprendizaje de la decepción. Capítulo: Pero ¿qué demonios quiere decir «Expresión»? Pamiela, 1. ${ }^{\circ}$ ed. $1989,2{ }^{a}$ ed. 1990, págs. 64 y 72.

13 MARCHÁN FIZ, S., Del arte objetual... págs. 323 y 324.
} 




Fig. 7. ANTÓN LAMAZARES. Maruja,1983.Técnica mixta sobre cartón, $164 \times 133 \mathrm{~cm}$. 


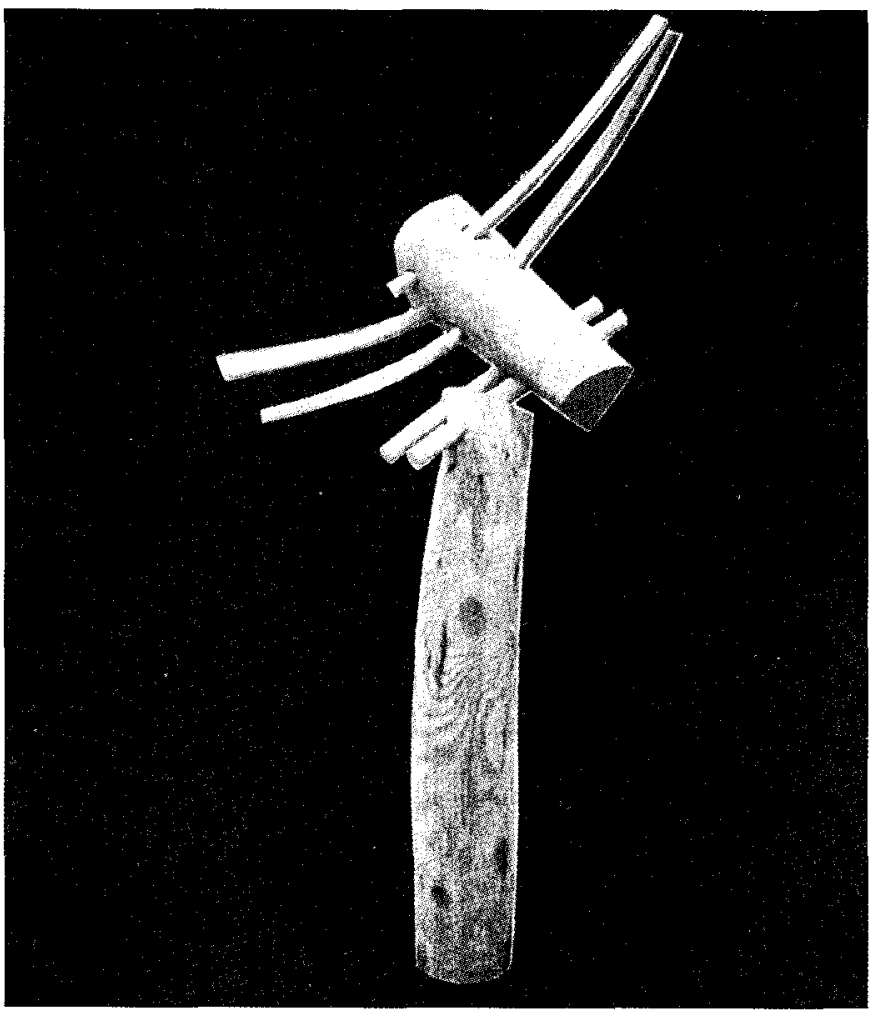

Fig. 8. IGNACIO BASALLO. S/T, 1982. Madera.

problema de la identidad nacional y la vanguardia, no ha sido resuelto en ninguno de los dos casos ${ }^{14}$.

De todos modos en el caso de Atlántica, aunque en defensa de la peculiaridad gallega, pretendió integrarse dentro del panorama artístico

14 Véase Fernández, H., en el Catálogo 10 contemporains espagnols, Travail e culture, 1990 , pág. 30. «Sólo en un caso, el de los escultores vascos, el auge se inscribe dentro de la transmisión de los saberes y de la genealogía precisa: la que continúa la obra de Jorge de Oteiza, ahora su profeta, pero antes un importante escultor de sombra alargada. Por otra parte el País vasco plantea un nuevo problema: las relaciones arte-nacionalidad. Si algún rincón dentro de las fronteras del «arte español» había condiciones para esperar esfuerzos y resultados en la vieja batalla de no nuevo, ese debía ser el Pasís Vasco. El lugar en que parecía posible acabar con la linealidad de las genealogías (...) si el genius loci no es una entelequia y hay relación entre arte y nacionalidad, el País Vasco era el laboratorio donde experimentarlo. Pero hasta el momento de allí sólo ha salido escultura, además archiformalista. Quizá sea demasiado pronto y queden esperanzas...» 
internacional tanto como en el nacional, y si bien artistas de décadas anteriores como Seoane o Reimundo Patiño, no lograron encontrar en su totalidad una dialéctica entre formas autóctonas y la vanguardia, artistas como Francisco Leiro, quien realiza una escultura de raíz gallega que a la vez es moderna y Menchu Lamas, quien recupera a través de símbolos y signos de carácter primitivo la tradición -asumiendo un arte internacional- parecen conseguirlo ${ }^{15}$.

Al mismo tiempo, el Atlantismo en relación con la «mirada oceánica» ${ }^{16}$ es decir la relación entre países bañados por el Atlántico en los que aparece una comunión con la naturaleza y un fuerte panteísmo, conlleva diferenciaciones con otras propuestas que el nombre de Atlántica trata de exponer en aras de esa especificidad, pero Atlántica ${ }^{17}$ no plantea su nacionalismo en una identidad de raza, ya que posee ese fuerte componente heteróclito, que abarca distintas propuestas: lo etnográfico, lo antropológico, «la mirada oceánica», la tradición de la piedra, el trabajo en madera y el mundo mítico, unidas a rasgos fundamentalmente ligados a propuestas internacionalistas.

\section{CONCLUSIONES}

A modo de epílogo convendría señalar lo que el grupo Atlántica significó en los años ochenta en Galicia, es decir, la ruptura con fórmulas artísticas agotadas, en las que la mirada a un arte de carácter folklorista y pintoresquista perpetuaba un endemismo que negaba toda posibilidad de irrupción de un arte de vanguardia. Si bien es cierto que como grupo no hubo un verdadero «corpus teórico», o una estética predominante que lo aglutinara, esto es más bien deudor de las prácticas artísticas de los ochenta, individualismo y subjetividad, que comparten con todo el ámbito internacional, así como la vuelta a la pintura o la utilización de los grandes formatos. Pero lo que sí es cierto, es que el grupo, fundado más por

\footnotetext{
15 Bozal, V., Arte del siglo xxx, pág. 635.

16 Véase comentarios sobre el concepto de «mirada oceáncia» en Seoane, $x$, Identidade e...pág. 247.

17 Véase CASTro, A., A cultura e a creatividade galegas cara ó ano 2000. Ed. Escola e sociedade. A Coruña, 1995, pág. 53. «Sin embargo, el nombre que escogieron los gallegos simboliza no sólo la defensa atlantista de especificidad antropológica y formal marcada por el horizonte del océano, sino también la patria estética de todos los países bañados por sus aguas, desde la mirada nórdica y romántica de los expresionistas - que tan afines fueron a los gallegos, puesto que el románico, el barroco y la vanguardia histórica, se podría inscribir en esta poética- como sintomas de un placer recuperado, libre y descomprometido"s.
} 
necesidad y por intereses comunes en la intención de revalorizar y proponer un cambio radical en el arte y la estética gallegos, fue un importante revulsivo en el arte del momento, que si bien tuvo poca importancia posteriormente, fue también debido al inexistente mercado del arte gallego, a la falta de un coleccionismo riguroso, de galerías comprometidas y de un impulso claro y definido por parte de la administración gallega del momento.

De todos modos, lo que sí parece claro, es que la existencia de Atlántica, muy corta, sirvió para que los artistas jóvenes iniciaran una andadura ligada al arte internacional que antes de la llegada de Atlántica hubiera sido casi imposible en Galicia.

Atlántica pues, desapareció como colectivo a mediados de los años ochenta, nada queda ya del espíritu que les llevó a la renovación total de la plástica, pero permaneció como referente para los artistas de la década siguiente, sirvió para que el arte en Galicia fuera conocido en el resto del país y su empuje revitalizó el mercado artístico logrando que el arte gallego abandonara su carácter tradicional y abordara un discurso vanguardista e internacional.

\section{BIBLIOGRAFÍA}

ARnAldo, J.: Fragmentos para una teoría romántica del arte. Novalis, F. SCHILLER, F. Y a. SCHLEGEL, h. VON KLEIST, F. HOLDERLING. (antología y edición de J. ARNALDO), Tecnos. Madrid, 1. a ed. 1987, 2. a ed. 1994.

AzúA, F.: El aprendizaje de la decepción. Capítulo: Pero ¿qué demonios quiere decir "expresión»?. Pamiela, 1. ${ }^{a}$ ed., 1989, 2. ${ }^{a}$ ed. 1990.

Bozal, V.: Arte del siglo xx en España. Pintores y escultores. 1939-1990. Espasa Calpe 1991.

Calvo Serraller, F.: Del futuro al pasado, vanguardia y tradición el arte español contemporáneo. Madrid, 1988.

- Escultura española actual: una generación para un fin de siglo. Fundación Lugar, Madrid 1992.

CASTRO, A.: Expresión Atlántica. Follas Novas. Santiago de Compostela, 1985.

- As mazás de Yoko Ono. Espiral Maior, ensaio. A Coruña, 1995.

Cranston, M.: El Romanticismo. Grijalbo Mondadori. Barcelona, 1997.

MARCHÁN FIZ, S.: La estética en la cultura moderna. Alianza Forma. Madrid, 1987, 1992.

- Del arte conceptual al arte del concepto. Primera y segunda ed. Corazón, comunicación Madrid, 1972, 1974. Tercera (1986), cuarta (1988), quinta (1990), sexta (1994), Akal, Madrid.

Rosenblum, R.: La pintura moderna y la tradición del romanticismo nórdico. Ed. castellana Alianza Editorial. Madrid, 1993.

SEOANE, X.: Identidade e convulsión. Palabra e imaxe da nova arte galega. Ed. Do Castro. A Coruña, 1990.

Vaugham, W.: Romanticismo y arte. Thames and Hudson. London, 1978 y 1994. Ed. Destino. Barcelona, 1995.

VVAA, CASTRO, A: A cultura e a creatividade galegas cara ó ano 2000. Ed. Escola e Sociedade. A Coruña, 1995. 
Catálogo: Atlántica-80. Casa de la Cultura de Baiona.

Catálogo: Atlántica. Centro Cultural de la Villa de Madrid, Delegación de Cultura, Acredisa, 1981.

Catálogo: Atlántica-83. Santiago de Compostela, 1983.

Catálogo: Imaxes nos oitenta. Museo do Povo Galego. Santiago de Compostela, 1984.

Catálogo: Antropoloxía e memoria. Visao actual de arte galega. Fundaçao Calouste Gulbenkian, Sociedade Nacional de Belas Artes. Lisboa, 1987.

Catálogo: Revisión dunha década(1978-1988) Arte galega. Auditorio de Galicia. Santiago de Compostela, 1990.

Catálogo: 10 contemporains Espagnols. Travail e Culture, 1990. 